\title{
Comments on Article: Agarwal S, Singh SN, Kumar R et al. Vitamin D: A Modulator of Allergic Rhinitis. Indian J Otolaryngol Head Neck Surg 71(Suppl 3):2225-2230
}

\author{
P. Lal $^{1} \cdot$ I. Tuli ${ }^{1}$
}

Received: 22 August 2020/Accepted: 1 September 2020/Published online: 8 September 2020

(C) Association of Otolaryngologists of India 2020

\section{Comments on Article}

Ref article published in your esteemed journal - Agarwal S, Singh SN, Kumar R et al. Vitamin D: A modulator of allergic rhinitis. Indian J Otolaryngol Head Neck Surg 71(Suppl 3):2225-2230. doi: https://doi.org/10.1007/ s12070-019-01697-9.

We would like to complement the authors for conducting a study on the role of Vitamin D in Allergic Rhinitis which may contribute towards optimization of the management protocols in such cases.

However, we wish to seek a clarification regarding the design of the study. The authors have designed the study as a case control study with the cases being patients of allergic rhinitis who were administered Vitamin D and the controls were non allergic rhinitis patients who were not administered Vitamin D. It is felt that for it to be an effective case control study the control group should include patients of allergic rhinitis who have not been administered Vitamin D unlike the cases.

The authors are requested to kindly throw light on the issue.

Publisher's Note Springer Nature remains neutral with regard to jurisdictional claims in published maps and institutional affiliations.

P. Lal

drpritilal@yahoo.com

1 Department of ENT, Vardhman Mahavir Medical College and Safdarjung Hospital, New Delhi 110029, India 